\title{
AKSESIBILITAS MERAPI PARK WORLD LANDMARK SEBAGAI DESTINASI YANG RAMAH BAGI DIFABEL
}

\author{
Luluk Nihayati ${ }^{1}$, Rekta Deskarina, ${ }^{2}$ \\ Program S1 Hospitality/Pariwisata Sekolah Tinggi Pariwisata Ambarukmo Yogyakarta \\ Jl. Ahmad Yani Jl. Ringroad Timur No.52, Pelem Mulong, Banguntapan, Kec. Banguntapan, Bantul, Daerah \\ Istimewa Yogyakarta 55198 luluknihayati1313@gmail.com ${ }^{1}$, rektadeskarina @ gmail.com
}

\begin{abstract}
Abstrak
Pariwisata yang aksesibel menjadi isu menarik dalam Konvensi PBB pada Rights of Disabled Person, bahwa akses dalam bidang pariwisata merupakan hak setiap orang. Difabel memiliki motivasi yang sama untuk berwisata seperti halnya masyarakat pada umumnya, tetapi kenyataannya mereka ridakmemperoleh kesempatan berwisata yang sama. Untuk membuka kesempatan bagi difabel, diperlukan fasilitas yang aksesibel dalam berwisata. Penelitian ini akan membandingkan temuan lapangan dengan teori yang ada secara kualitatif. Di samping itu juga dilakukan koding terhadap hasil wawancara dan kemudian dilanjutkan dengan mengelompokkan hasil koding tersebut ke dalam tema yang telah ditentukan untuk selanjtnya dianalisa. Peneliti perlu melakukan penelitian tentang kelayakan aksesibilitas bagi kaum difabel, penelitian serupa di Merapi Park World Landmark belum pernah dilakukan. Sehingga dapat diketahui kelayakan aksesibilitas yang dapat membuat wisatawan difabel merasa nyaman dan tidak mendapatkan kendala selama berwisata. Kondisi eksisting fasilitas diukur dari kondisi ketersediaan dan kesesuaian, standar yang digunakan dalam penilaian merujuk pada Peraturan Menteri Pekerjaan Umum Nomor 14 Tahun 2017, tentang Persyaratan Kemudahan Bangunan Gedung. Terdapat enam aspek yang dinilai yaitu jalur pedestrian, jalur pemandu, area parkir, ramp, toilet, rambu dan marka. Jalur pedestrian dan ramp merupakan aspek yang telah memenuhi standar baik dari kesesuaian maupun ketersediaan. Aspek rambu dan marka serta jalur pemandu tidak memenuhi standar sama sekali. Dengan demikian dapat ditarik kesimpulan bahwa fasilitas yang tersedia di Merapi World Landmark bagi difabel belum memenuhi standar dan belum dikatakan layak.
\end{abstract}

Kata kunci: Prioritas Peningkatan, Prasarana Berkelanjutan, Analisis AHP.

\begin{abstract}
Accessible tourism is an interesting issue in the UN Convention on the Rights of Disabled Persons, that access in the field of tourism is everyone's right. The disabled have the same motivation to travel as the community in general, but in reality they do not get the same travel opportunities. To open up opportunities for disabled people, accessible facilities for traveling are needed. This study will compare field findings with existing theories qualitatively. In addition, coding was also carried out on the results of the interview and then proceed with the grouping of the results of the coding into themes that have been determined for further analysis. Researchers need to conduct research on the feasibility of accessibility for people with disabilities, similar research at Merapi Park World Landmark has never been done. So that it can be seen the feasibility of accessibility that can make disabled tourists feel comfortable and not get obstacles during the tour. The existing condition of the facility is measured by the conditions of availability and suitability, the standard used in the assessment refers to the Regulation of the Minister of Public Works No. 14 of 2017, concerning the Ease of Building Requirements. There are six aspects assessed, namely pedestrian paths, guide lanes, parking areas, ramps, toilets, signs and markers. Pedestrian and ramp lines are aspects that have met the standards of both compatibility and availability. The sign and marking aspects as well as the guide lines do not meet the standard at all. Thus it can be concluded that the facilities available at Merapi World Landmark for the disabled have not met the standards and have not been said to be feasible.
\end{abstract}

Keywords: accessibility, disabled, feasibility study, tourists.

\section{PENDAHULUAN}

Ketentuan terkait difabel dalam dunia pariwisata tertuang dalam Undang-undang No.10 Tahun 2009 pasal 21 yang menyebutkan bahwa wisatawan yang memiliki keterbatasan fisik, anakanak, dan lanjut usia (lansia) berhak mendapatkan fasilitas khusus sesuai dengan kebutuhannya. Berdasar jumlah difabel yang mencapai 34.147 jiwa pada tahun 2009 (Badan Pusat Statistik DIY, 2010) dan semakin meningkat dari tahun sebelumnya, maka Daerah Istimewa Yogyakarta seharusnya mengambil kebijakan mengarah pada pembangunan kota dan khususnya obyek wisata yang aksesibel bagi semua kalangan, baik warga kota maupun wisatawan. Ini berarti terpenuhinya sarana dan fasilitas yang aksesibel bagi kaum difabel 
merupakan hal yang harus dan wajib dilaksanakan untuk menjamin kesamaan kesempatan hidup.

Pembangunan kota yang aksesibel, khususnya pada destinasi wisata, akan dapat diwujudkan jika mengacu pada peraturan pembangunan gedung dan lingkungan yaitu Peraturan Menteri Pekerjaan Umum Nomor 14 Tahun 2017, tentang Persyaratan Kemudahan Bangunan Gedung. Destinasi wisata merupakan kawasan publik yang diperuntukkan untuk khalayak umum. Salah satu tujuan wisata baru yang ada di Yogyakarta adalah Merapi Park The World Landmark. Merapi Park The World Landmark berada di lereng gunung Merapi. Miniatur landmark dunia seperti menara Eiffel, patung liberty dan Big Ben di London menjadi sudut foto yang sangat menarik bagi wisatawan. Selain berbagai miniatur bangunan terkenal, Merapi Park The World Landmark juga menyuguhkan pemandangan indah Gunung Merapi. Sebagai destinasi wisata baru, diperlukan analisis lebih lanjut apakah pengembangan destinasi wisata Merapi Park The World Landmark ramah terhadap wisatawan difabel, sehingga penelitian ini perlu untuk dilakukan.

Tujuan dari penelitian ini adalah mengidentifikasi kebutuhan wisatawan difabel saat mengunjungi Merapi Park World Landmark, serta menjelaskan kelayakan aksesibilitas bagi wisatawan difabel di Merapi Park World Landmark

\subsection{Lokasi Penelitian}

Lokasi penelitian di Merapi Park The World Landmark, Jalan Kaliurang $\mathrm{Km}$ 25, Kelurahan Hargobinangun, Kecamatan Pakem, Sleman. Merapi Park The World Landmark terletak di kawasan Kaliurang yang berada di lereng gunung Merapi, dimana kawasan Kaliurang merupakan salah satu ikon wisata Yogyakarta yang cukup populer.

\subsection{Populasi dan Sampel Penelitian}

Populasi dan sampel dalam penelitian ini adalah wisatawan khususnya wisatawan difabel dan pengelola Merapi Park The World Landmark. Sampel penelitian ditentukan dengan metode purposive sampling yaitu penarikan sampel yang sesuai dengan tujuan penelitian.

\subsection{Teknik Pengumpulan Data}

Teknik pengumpulan data dibedakan menjadi data primer dan data sekunder.

\section{a. Observasi Lapangan}

Teknik pengumpulan data dengan cara mengamati dan mencatat secara sistematik unsurunsur yang tampak dalam suatu objek penelitian (Nawawi dan Martini dalam Afifuddin dan Saebani, 2012). Pengamatan empirik di lapangan meliputi kondisi fasilitas yang aksesibel untuk difabel di Merapi Park The World Landmark, antara lain area parkir, pedestrian, ramp, toilet, ubin pemandu (guiding block), serta rambu dan marka.

\section{b. Wawancara}

Wawancara adalah teknik pengumpulan data dengan cara menanyakan sesuatu kepada seseorang yang menjadi informan dengan bercakap-cakap secara tatap muka. Wawancara dilakukan dengan menitikberatkan pada penggalian informasi terhadap key person dengan teknik wawancara yang mendalam (in-depth interview) dan dengan teknik wawancara terstruktur mengacu pada fokus permasalahan yang diteliti. Wawancara dengan difabel dilakukan guna mengetahui apa yang mereka harapkan ketika melakukan kegiatan wisata. c. Dokumentasi

Dokumentasi adalah teknik pengumpulan data dengan cara mencari bukti-bukti dari sumber non manusia terkait dengan objek yang diteliti (Afifuddin dan Saebani, 2012) yang berupa tulisan, gambar, atau karya-karya monumental dari seseorang (Sugiyono, 2013). Pengambilan data berupa foto-foto, sketsa gambar, dan catatan-catatan terkait fokus yang diteliti.

\section{d. Data Sekunder}

Data sekunder dikumpulkan sesuai dengan permasalahan penelitian. Data sekunder diperoleh dari studi literatur yaitu dari peraturan perundangundangan, buku, jurnal dan internet.

\subsection{Teknik Analisis Data}

Penelitian ini akan membandingkan temuan lapangan (dengan menyusun secara sistematis data yang diperoleh dari hasil wawancara, catatan lapangan, dan dokumentasi), dengan kecocokan teori yang ada secara kualitatif. Selain itu, juga dilakukan koding terhadap hasil wawancara dan kemudian dilanjutkan dengan mengelompokkan hasil koding tersebut ke dalam tema-tema yang telah ditentukan untuk kemudian dianalisis. Kemudian menarik kesimpulan berdasarkan data yang didapatkan selama penelitian berlangsung.

\section{HASIL DAN PEMBAHASAN}

2.1 Fasilitas Aksesibel Untuk Difabel

a. Analisis Kelengkapan Aksesibilitas Bagi Difabel

Penelitian mengenai kelengkapan sarana dan fasilitas di Merapi Park World Landmark yang aksesibel untuk semua kalangan wisatawan termasuk bagi wisatawan difabel khususnya di lingkungan atau luar gedung, akan melihat dari enam hal berikut, antara lain: jalur pedestrian; jalur pemandu (guiding block), area parkir, ramp, toilet, rambu dan marka. Hal ini merujuk pada Peraturan Menteri Pekerjaan Umum Nomor 14 Tahun 2017, tentang Persyaratan Kemudahan Bangunan Gedung.

Menurut Peraturan Menteri Pekerjaan Umum Nomor 14 Tahun 2017 yang dibuat untuk memberikan acuan bagi kegiatan pembangunan yang meliputi perancangan dan pelaksanaan konstruksi serta pemanfaatan bangunan gedung dan lingkungan yang aksesibel bagi semua orang dengan mengutamakan semua orang termasuk difabel. Tujuan kebijakan ini adalah mewujudkan kesamaan, kesetaraan, kedudukan dan hak kewajiban serta peningkatan peran difabel. 
Jurnal Arsitektur, Kota dan Permukiman (LOSARI)

Tabel 1. Analisis Kelengkapan Aksesibilitas Bagi Difabel

\begin{tabular}{|c|c|c|c|}
\hline \multirow{2}{*}{ FASILITAS } & \multicolumn{3}{|c|}{ KONDISI } \\
\hline & Seharusnya & Senyatanya/Eksisting & Ketersediaan \\
\hline 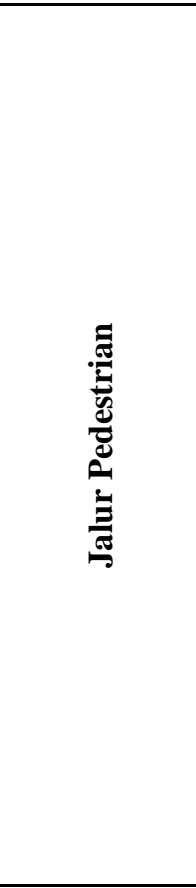 & $\begin{array}{l}\text { Lebar minimum } 110 \mathrm{~cm} \text { untuk jalur searah } \\
\text { dan } 180 \mathrm{~cm} \text { untuk jalur dua arah; } \\
\text { Memiliki jalur yang landai maks } 5^{\circ} \text {; } \\
\text { Setiap jarak } 900 \mathrm{~cm} \text { diharuskan } \\
\text { terdapat permukaan datar (bordes) dengan } \\
\text { panjang minimal } 120 \mathrm{~cm} \text {; } \\
\text { Permukaan jalan rata, tidak licin, dan tahan } \\
\text { cuaca; } \\
\text { Tepi pengaman (kanstin) tinggi maks } 10 \mathrm{~cm} \\
\& \text { lebar maks } 15 \mathrm{~cm} \text { sepanjang jalur } \\
\text { pedestrian; } \\
\text { Ramp pada jalur pedestrian diletakkan di } \\
\text { setiap persimpangan, prasarana ruang } \\
\text { pejalan kaki yang memasuki pintu keluar } \\
\text { masuk kaveling; } \\
\text { Tersedia pegangan rambat (handrail) }\end{array}$ & $\begin{array}{l}\text { Sesuai } \\
\text { Sesuai } \\
\text { Sesuai }\end{array}$ & $\begin{array}{l}\text { (tersedia) } \\
\text { (tersedia) } \\
\text { (tersedia) } \\
\text { (tersedia) } \\
\text { (tersedia) } \\
\text { (tersedia) }\end{array}$ \\
\hline 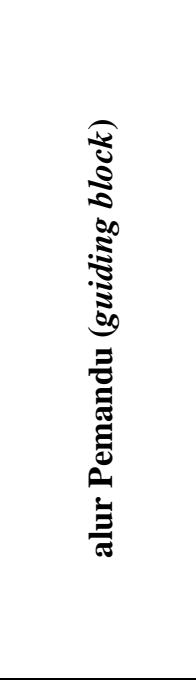 & $\begin{array}{l}\text { Menggunakan standard ubin pemandu yang } \\
\text { bertekstur garis dan bulat (untuk tunanetra); } \\
\text { Ubin pemandu dipasang pada bagian tepi } \\
\text { jalur pedestrian untuk memudahkan } \\
\text { pergerakan penyandang disabilitas tunanetra } \\
\text { termasuk penyandang gangguan penglihatan } \\
\text { yang hanya mampu melihat sebagian (low } \\
\text { vision); } \\
\text { Ubin pemandu dibuat dengan material yang } \\
\text { kuat dan tidak licin, serta menggunakan } \\
\text { warna kontras dengan ubin eksisting seperti } \\
\text { kuning, jingga, atau warna lainnya sehingga } \\
\text { mudah dikenali oleng penyandang gangguan } \\
\text { penglihatan yang hanya mampu melihat } \\
\text { sebagian (low vision) }\end{array}$ & & $\begin{array}{l}\text { (tidak tersedia) } \\
\text { (tidak tersedia) } \\
\text { (tidak tersedia) }\end{array}$ \\
\hline 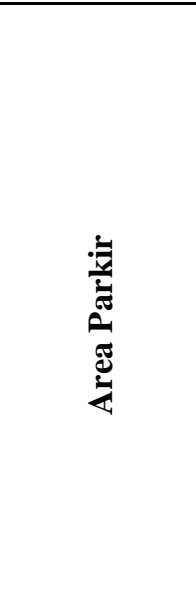 & $\begin{array}{l}\text { Jarak pencapaian tempat parkir } \\
\text { menuju bangunan/ fasilitas, maksimum } 60 \\
\text { meter; } \\
\text { Ditandai dengan adanya simbol khusus } \\
\text { penyandang disabilitas; } \\
\text { Dimensi area parkir single memiliki lebar } \\
320-360 \mathrm{~cm} \text {; } \\
\text { Dimensi passanger loading zone (lebar } \\
\text { min.370 cm); } \\
\text { Jumlah lot parkir difabel } 1 \text { : } 50 \text { dari } \\
\text { ketersediaan lot parkir }\end{array}$ & Sesuai & $\begin{array}{c}\text { (tersedia) } \\
\text { (tidak tersedia) } \\
\text { (tidak tersedia) } \\
\text { (tidak tersedia) } \\
\text { (tidak tersedia) }\end{array}$ \\
\hline
\end{tabular}




\begin{tabular}{|c|c|c|c|}
\hline 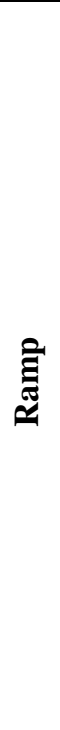 & $\begin{array}{l}\text { Tekstur lantai tidak licin; } \\
\text { Derajat kemiringan maksimum } 5^{\circ} \text {; } \\
\text { Lebar jalur minimum } 95 \mathrm{~cm} \text { tanpa } \\
\text { tepi pengaman \& minimum } 120 \mathrm{~cm} \text { dengan } \\
\text { tepi pengaman/kanstin; } \\
\text { Permukaan datar (bordes) berukuran } \\
\text { panjang minimum } 160 \mathrm{~cm} \text {; } \\
\text { Tepi pengaman (kanstin/low curb) paling } \\
\text { rendah memiliki ketinggian } 10 \mathrm{~cm} \text { yang } \\
\text { berfungsi sebagai pemandu arah bagi } \\
\text { penyandang disabilitas netra dan penahan } \\
\text { roda kursi roda agar tidak terperosok keluar } \\
\text { ramp; }\end{array}$ & $\begin{array}{c}\text { Sesuai } \\
\text { Sesuai, hanya di } \\
\text { beberapa bagian saja } \\
\text { Sesuai, hanya di } \\
\text { beberapa bagian saja } \\
\text { Sesuai } \\
\text { Sesuai }\end{array}$ & $\begin{array}{l}\text { (tersedia) } \\
\text { (tersedia) } \\
\text { (tersedia) }\end{array}$ \\
\hline 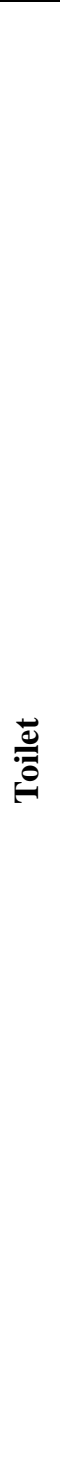 & $\begin{array}{l}\text { Terdapat simbol cetak timbul "penyandang } \\
\text { cacat" pada pintu toilet bagian luar; } \\
\text { Luas ruang dalam disabilitas paling sedikit } \\
\text { memiliki ukuran } 152,5 \mathrm{~cm} \text { X } 227,5 \mathrm{~cm} \\
\text { dengan mempertimbangkan ruang gerak } \\
\text { pengguna kursi roda; } \\
\text { Lebar pintu minimal } 90 \mathrm{~cm} \text { (dapat diakses } \\
\text { oleh kursi roda); } \\
\text { Daun pintu toilet disabilitas pada dasarnya } \\
\text { membuka ke arah luar toilet, sehingga } \\
\text { memberikan ruang bebas yang cukup untuk } \\
\text { pengguna kursi roda melakukan manuver } \\
\text { berputar } 180 \text { dan membuka/ menutup pintu; } \\
\text { Pada bagian atas luar pintu toilet disediakan } \\
\text { lampu alarm (panic lamp) yang akan } \\
\text { mdiaktifkan oleh pengguna toilet dengan } \\
\text { menekan tombol darurat (emergency sound } \\
\text { button) atau menarik tuas yan tersedia di } \\
\text { dalam toilet ketika terjadi keadaan darurat; } \\
\text { Pintu toilet perlu dilengkapi dengan plat } \\
\text { tendang di bagian bawah pintu untuk } \\
\text { pengguna kursi roda dan tunanetra; } \\
\text { Ketinggian wastafel maksimum } 85 \text { cm } \\
\text { disesuaikan dengan level ketinggian kursi } \\
\text { roda; } \\
\text { Wastafel harus memiliki ruang gerak di } \\
\text { bawahnya sehingga tidak menghalangi lutut } \\
\text { dan kaki pengguna kursi roda; } \\
\text { Tersedia pegangan rambat / handrail }\end{array}$ & $\begin{array}{c}\text { Sesuai } \\
\text { Tidak sesuai } \\
\text { Tidak sesuai } \\
\text { Tidak sesuai }\end{array}$ & $\begin{array}{c}\text { (Tersedia) } \\
\text { (Tersedia) } \\
\text { (Tidak tersedia) }\end{array}$ \\
\hline
\end{tabular}




\begin{tabular}{|l|l|l|l|}
\hline & $\begin{array}{l}\text { Menunjukkan pada arah dan tujuan jalur } \\
\text { pedestrian, fasilitas KM/WC umum, telpon } \\
\text { umum, parkir khusus penyandang cacat, } \\
\text { Telepon dan ATM; } \\
\text { Rambu informasi dengan huruf timbul atau } \\
\text { huruf Braille yang dapat dibaca oleh tuna } \\
\text { netra dan penyandang cacat lain; } \\
\text { Karakter dan latar belakang rambu harus } \\
\text { dibuat dari bahan yang tidak silau. Karakter } \\
\text { dan simbul harus kontras dengan latar } \\
\text { belakangnya, apakah karakter terang di atas } \\
\text { gelap, atau sebaliknya; } \\
\text { Penempatan yang sesuai dan tepat serta } \\
\text { bebas pandang tanpa penghalang; } \\
\text { Tidak mengganggu arus (pejalan kaki dll) } \\
\text { dan sirkulasi (buka/tutup pintu, dll). }\end{array}$ & (Tidak tersedia) \\
\hline
\end{tabular}

\section{b. Analisis Kondisi Eksisting Aksesibilitas Bagi Difabel}

1) Jalur Pedestrian

Permukaan jalan cukup rata dan tidak licin. Lebar jalur pedestrian utama (jalur 2 arah) yaitu 180-200 cm, sedangkan lebar jalur pedestrian searah hanya $80 \mathrm{~cm}$. Beberapa bagian jalur sudah terdapat tepi pengaman (kanstin) dengan tinggi maksimal $10 \mathrm{~cm}$, namun cukup banyak bagian yang belum terdapat tepi pengaman (kanstin). Ramp pada jalur pedestrian diletakkan di setiap persimpangan dan menuju pintu keluar masuk bangunan atau kaveling. Kelandaian jalur pedestrian beberapa bagian derajat kemiringannya $5^{\circ}$, tetapi beberapa bagian lainnya masih melebihi $5^{\circ}$ yaitu $\pm 10^{\circ}-15^{\circ}$.

2) Jalur Pemandu (guiding block)

Pada pedestrian Merapi World Landmark, tampak belum tersedia jalur pemandu (guiding block) yang diperuntukkan untuk difabel tunanetra. Dari mulai jalur sirkulasi arah masuk pintu utama (gerbang utama) sampai jslur pedestrian di dalam taman belum tersedia jalur pemandu (guiding block). Tidak adanya fasilitas jalur pemandu (guiding block) ini menyebabkan tidak terpenuhinya asas keselamatan, kemudahan, dan kemandirian wisatawan difabel tunanetra untuk menuju dan berada di taman tersebut. Kebutuhan dari difabel tunanetra adalah disediakannya jalur pemandu dengan material standard ubin pemandu yang bertekstur garis-garis linier dan tekstur bulat, serta menggunakan warna yang kontras seperti jingga atau kuning sehingga mudah dikenali oleh penyandang gangguan penglihatan sebagian (low vision).Jalur pemandu (guiding block) tersebut harus mengikuti jalur sirkulasi (tidak boleh terputus) dan mengarahkan ke semua fasilitas di taman.

\section{3) Area Parkir}

Untuk area parkir menuju pintu masuk Merapi World Landmark ini dikatakan cukup/sesuai kebutuhan oleh wisatawan difabel. Jarak dari area parkir menuju pintu masuk atau gerbang utama \pm 10 meter, tersedia drop-off area, danpada area di dekat pintu masuk menyediakan stand peminjaman alat bantu aksesibilitas seperti seperti kursi roda sesuai dengan kebutuhan tunadaksa. Stand peminjaman alat ini bertujuan untuk membantu wisatawan difabel yang menggunakan motor/kendaraan umum yang mengalami kesusahan dalam membawa alat bantu aksesibilitasnya. Namun kekurangan dari fasilitas ini adalah material pada area parkir masih berupa tanah/bebatuan sehingga kurang memenuhi asas kemudahan dan keselamatan terutama bagi pengguna kursi roda dan tunanetra seperti pada gambar 3, juga belum tersedianya lot parkir khusus untuk difabel baik di area parkir motor maupun mobil.

4) Ramp

Ramp pada jalur pedestrian diletakkan di setiap persimpangan dan menuju pintu keluar masuk bangunan atau kaveling. Pada sirkulasi pintu utama keluar masuk wisatawan tersedia ramp dengan lebar jalur $100 \mathrm{~cm}$, dilengkapi tepi pengaman (kanstin) dengan tinggi $10 \mathrm{~cm}$ dan handrailsdengan ketinggian $80 \mathrm{~cm}$, namun derajat kemiringan melibihi $5^{\circ}$.

5) Toilet

Beberapa hal yang belum memenuhi standard aksesibilitas pada toilet yaitu lebar pintu masuk hanya $80 \mathrm{~cm}$, kurang leluasa untuk keluar masuk difabel tunadaksa. Ukuran ruang 
dalam toilet $150 \times 180 \mathrm{~cm}$, belum tersedia pegangan rambat (handrail), daun pintu toilet tidak membuka ke arah luar, sehingga kurang leluasa untuk difabel tunadaksa karena harus memiliki ruang bebas yang cukup untuk manuver kursi roda. Pintu toilet belum dilengkapi dengan plat tendang di bagian bawah pintu, dan pada bagian atas pintu toilet belum dilengkapi dengan lampu alarm (panic lamp) yang akan membantu wisatawan difabel jika terjadi keadaan darurat di dalam toilet.

\section{6) Rambu dan Marka}

Persimpangan jalur pedestrian atau yang mengarah ke fasilitas-fasilitas lain belum tersedia rambu dan marka untuk difabel. Rambu-rambu informasi yang tersedia menggunakan tulisan latin, tidak dilengkapi dengan huruf braille sehingga menyulitkan difabel tunanetra.

\section{KESIMPULAN \& SARAN}

Hasil yang diperoleh di lapangan berupa data primer kondisi eksisting fasilitas. Kondisi eksisting fasilitas diukur dari kondisi ketersediaan dan kesesuaian.Terdapat enam aspek pada fasilitas yang dinilai yaitu jalur pedestrian, jalur pemandu, area parkir, ramp, toilet serta rambu dan marka.

Dari keenam aspek, jalur pedestrian dan ramp merupakan aspek yang telah memenuhi standar aksesibilitas baik dari kesesuaian maupun ketersediaan. Aspek rambu dan marka serta jalur pemandu tidak memenuhi standar aksesibilitas sama sekali baik kesesuaian maupun ketersediaan. Dengan melihat hasil penelitian dan analisa, dapat ditarik kesimpulan bahwa fasilitas yang tersedia di Merapi World Landmark belum memenuhi standar aksesibilitas dan belum dikatakan layak bagi difabel. Dari kesimpulan tersebut maka peneliti dapat mmeberikan masukan untuk di Merapi World Landmark, berkaitan dengan pengembangan fasilitas agar aksesibel bagi difabel:

a. Penyediaan jalur pemandu (guiding block) sesuai dengan standar aksesibilitas difabel.

b. Penyediaan area parkir sesuai dengan standar aksesibiltas difabel.

c. Penyediaan rambu dan marka sesuai dengan standar aksesibilitas difabel

d. Penyesuaian toilet dengan standar aksesibilitas difabel.

\section{DAFTAR PUSTAKA}

Afifuddin dan Beni Ahmad Saebani. Metodologi Penelitian Kualitatif. Pustaka Setia, Bandung. 2012.

Badan Pusat Statistik. Daerah Istimewa Yogyakarta Dalam Angka 2010.Badan Pusat Statistik, Provinsi Daerah Istimewa Yogyakarta. 2010. Lalita Sen. The Limitation and Scope of Accessible Tourism in India. http://www.tc.gc.ca/eng/policy/transed2007pages-1172-414.htm 2007. (Diakses 12 Agustus 2018)

Sugiyono. Memahami Penelitian Kualitatif.

Alfabeta, Bandung. 2013.

Yaniv. Poria, Arie Reichel, dan Yael Brandt. The

Flight Experiences of People with

Disabilities: An Exploratory Study. Journal

of Travel Research.

http://jtr.sagepub.com/content/49/2/216 2010.

(Diakses 17 Mei 2019)

Peraturan Menteri Pekerjaan Umum Nomor 14

Tahun 2017, tentang Persyaratan Kemudahan

Bangunan Gedung.

Undang-undang Nomor 10 tahun 2009 Tentang Pariwisata

Undang-Undang Republik Indonesia Nomor 4 Tahun 1997 tentang Penyandang Cacat 